OPEN ACCESS

Edited by:

Jian Liu,

University of British Columbia

Okanagan, Canada

Reviewed by: Hossein Yadegari,

Imperial College London, United Kingdom

Fadwa Dababneh,

Applied Science Private University,

Jordan

${ }^{*}$ Correspondence:

Duygu Karabell

duygu.kaus@ipa.fraunhofer.de

Specialty section:

This article was submitted to Electrochemical Energy Conversion and Storage,

a section of the journal

Frontiers in Energy Research

Received: 14 August 2020 Accepted: 02 November 2020 Published: 24 November 2020

Citation: Karabelli D, Kiemel S, Singh S, Koller J, Ehrenberger $S$, Miehe R, Weeber $M$ and Birke KP (2020) Tackling xEV Battery Chemistry in View of Raw Material Supply Shortfalls.

Front. Energy Res. 8:594857. doi: 10.3389/fenrg.2020.594857

\section{Tackling xEV Battery Chemistry in View of Raw Material Supply Shortfalls}

\author{
Duygu Karabelli ${ }^{1 *}$, Steffen Kiemel ${ }^{1}$, Soumya Singh ${ }^{1}$, Jan Koller ${ }^{2}$, Simone Ehrenberger ${ }^{3}$, \\ Robert Miehe ${ }^{1}$, Max Weeber ${ }^{1}$ and Kai Peter Birke ${ }^{1,4}$ \\ ${ }^{1}$ Fraunhofer Institute for Manufacturing Engineering and Automation IPA, Stuttgart, Germany, ${ }^{2}$ Fraunhofer Institute for \\ Manufacturing Engineering and Automation IPA, Bayreuth, Germany, ${ }^{3}$ Institute of Vehicle Concepts, German Aerospace Center \\ (DLR), Stuttgart, Germany, ${ }^{4}$ Institute for Photovoltaics, University of Stuttgart, Stuttgart, Germany
}

The growing number of Electric Vehicles poses a serious challenge at the end-of-life for battery manufacturers and recyclers. Manufacturers need access to strategic or critical materials for the production of a battery system. Recycling of end-of-life electric vehicle batteries may ensure a constant supply of critical materials, thereby closing the material cycle in the context of a circular economy. However, the resource-use per cell and thus its chemistry is constantly changing, due to supply disruption or sharply rising costs of certain raw materials along with higher performance expectations from electric vehicle-batteries. It is vital to further explore the nickel-rich cathodes, as they promise to overcome the resource and cost problems. With this study, we aim to analyze the expected development of dominant cell chemistries of Lithium-lon Batteries until 2030, followed by an analysis of the raw materials availability. This is accomplished with the help of research studies and additional experts' survey which defines the scenarios to estimate the battery chemistry evolution and the effect it has on a circular economy. In our results, we will discuss the annual demand for global e-mobility by 2030 and the impact of Nickel-Manganese-Cobalt based cathode chemistries on a sustainable economy. Estimations beyond 2030 are subject to high uncertainty due to the potential market penetration of innovative technologies that are currently under research (e.g. solid-state Lithium-lon and/or sodium-based batteries).

Keywords: xEV, Li-ion batteries, NMC chemistry, raw materials, circular economy, end-of-life, recycling

\section{INTRODUCTION}

Since the commercial development of Li-ion cells in 1991 by Sony (Nishi, 2001), the Lithium-ion battery (LIB) market is continuously growing. The market for rechargeable LIBs is currently divided into three main segments: consumer electronics, electromobility (e-mobility) applications and stationary batteries. Within these listed segments, e-mobility is essential for achieving the climate targets. E-mobility essentially means much more than driving an Electric Vehicle (EV). E-bikes and e-scooters have gained popularity and they are increasingly materializing in our daily lives. The battery chemistry used in EVs can also be applied in other mobility solutions (Vezzini, 2014). However, expected lifetime of e-bikes and e-scooters are relatively shorter as compared to xEV due to the high cycle number at high C-rates in a short period of use (Oeser, 2018; Baeva et al., 2019).

EVs are strong contributors to the expanding market of Li-ion cells because an EV battery system is much larger in $\mathrm{Ah}$ as compared to consumer applications. Automotive traction batteries can contain up to 7,000-10,000 single cylindrical cells of the formats 18,650-type (18 mm diameter, 
$65 \mathrm{~mm}$ height) or 21,700-type (21 $\mathrm{mm}$ diameter, $70 \mathrm{~mm}$ height) (Quinn et al., 2018). In consequence, the global demand for raw materials of Li-ion cells will rise tremendously in the upcoming years. In case the local grid demands offer attractive return of investments, the stationary applications employing Li-ion cells would also be of great interest. In Australia, for example, Tesla has built up a 129 MWh stationary battery consisting of cylindrical cell modules, mainly same as those in the Tesla automobile (Perkins, 2018; Keck et al., 2019).

Nevertheless, what makes Li-ion so unique, why was it worth receiving the Nobel price of chemistry in 2019 (Manthiram, 2020), and will it be or stay the ruling battery technology? Indeed, the ingredients of success are quite uniquely called intercalation electrodes and Solid Electrolyte interphase (SEI) (Nishi, 2001; Handbuch Lithium-Ionen-Batterien, 2013; Pistoia, 2014; Luntz et al., 2015; Liu et al., 2016; Zubi et al., 2018). No question that some replications with mobile ions other than $\mathrm{Li}$ ions are also feasible. However, the important discussion lies in the question if the replication can ever beat the original. The ideal intercalation principle allows to insert and extract ions into and from a lattice host structure without any volume changes. Indeed, such a "zero strain" material exists in reality, it is $\mathrm{Li}_{4} \mathrm{Ti}_{5} \mathrm{O}_{12}$, capable to insert and extract three Li atoms with nearly zero strain expansion (about $0.2-0.3 \%$ ) which results in achieving extremely high cycles with improved safety (Zaghib et al., 1999; Xu et al., 2017). One may argue that this is also due to the favorable voltage of about $1.5 \mathrm{~V}$ vs. $\mathrm{Li}^{+} / \mathrm{Li}$, which evidently suppresses electrolyte decomposition. However, the less the volume changes upon charge and discharge of an intercalation material, the better the expected cycle behavior. The volume expansion of the host materials also depends on the co-intercalation of solvent species. Similar to hydrogen, lithium offers very small ions. Smaller the ion, lesser the expected volume changes of the host lattice when the ions are inserted and extracted. In fact, any alternative to Liions should contain larger monovalent ions. If multivalent ions are anticipated, the discussion does not only include the size but also possibly much unfavorable diffusions coefficients than those of monovalent ions (Levi and Aurbach, 2005; Li et al., 2020). A similar uniqueness holds for the SEI. A breakthrough discovery was the fact that $\mathrm{LiAsF}_{6}$ and $\mathrm{LiPF}_{6}$ based electrolytes, dissolved in certain carbonate mixtures consisting of EC (ethylene carbonate), DMC (dimethylcarbonate), EMC (ethylmethylcarbonate) and DEC (diethylcarbonate), build SEIs on graphite electrodes (the negative one), which last a whole battery life with acceptable degradation (Aurbach et al., 1995; Peled and Menkin, 2017). Evidently, only $\mathrm{LiPF}_{6}$ survived since $\mathrm{LiAsF}_{6}$ was not feasible due to reasons of toxicity. But the most interesting aspect is that since 1991, around $95 \%$ of the electrolyte composition stayed unchanged, proving the uniqueness of this electrolyte system. So, any replication attempt with other mobile ions has to find a comparable electrolyte system at first. Cells employing so-called solid electrolytes (Zheng et al., 2018) are not in discussion to just replace the liquid electrolyte. The hope is to employ solid electrolytes in order to use metallic negative electrodes and improve the energy density. However, actual research results do not show that this option would be available in widespread commercial applications before 2030. It has to be additionally emphasized that tremendous production capacities (Gigafactories) (Kurland, 2019; Fan et al., 2020) and automotive V-Model life cycle (Kumar et al., 2009; Liu et al., 2016) will prevent any fast switch to other battery cell technologies. Hence, it is established that Li-ion technology will be prominent in the near future, however its chemistry and materials are uncertain.

Discussing the materials for all the battery components is not within the scope of this paper, thus the most challenging one is selected, the cathode (positive electrode). The negative electrode is somehow settled. Graphite has a potential near lithium, and only the combination of graphite and electrolyte allows long lasting SEIs, so no improvements are possible besides adding some silicon (Xiang et al., 2011; Chakrapani et al., 2012). The positive electrode, however, has still a tremendous tuning factor, if we look at the so-called $4 \mathrm{~V}$ materials. Particularly NickelManganese-Cobalt (NMC) and Nickel-Cobalt-Aluminium (NCA) based electrodes have unified much advantages such as capacity, long life, acceptable safety, capacity ( $\mathrm{mAh} / \mathrm{g})$, as well as voltage slope as function of the state of charge ( $\mathrm{SoC}$ ) which is very favorable for many applications (Barré et al., 2013; Thielmann et al., 2015; Dominko et al., 2019). Alternative cathode materials with higher capacity have often been discussed in the literature, such as manganese vanadates $\left(\mathrm{Mn}\left(\mathrm{VO}_{3}\right)_{2} \cdot \mathrm{yH}_{2} \mathrm{O}\right)$ (Pillot, 2017), but they failed due to unfavorable voltage as function of the SoC as well as too low absolute mean values of the open circuit voltage vs. Li. Though $\mathrm{LiFePO}_{4}$ is a very interesting and already successfully commercialized cathode candidate (Handbuch Lithium-Ionen-Batterien, 2013; Pillot, 2017; Zubi et al., 2018), it is rather a $3 \mathrm{~V}$ than a $4 \mathrm{~V}$ material. Hence, $\mathrm{LiFePO}_{4}$ struggles in energy density over NMC.

In order to consequently optimize $\mathrm{NMC}$, researchers started to tune the $\mathrm{N}: \mathrm{M}: \mathrm{C} 1: 1: 1\left(\mathrm{LiNi}_{1 / 3} \mathrm{Mn}_{1 / 3} \mathrm{Co}_{1 / 3} \mathrm{O}_{2}\right)$ formulation to more Ni-rich ones such as 5:3:2 $\left(\mathrm{LiNi}_{0.5} \mathrm{Mn}_{0.3} \mathrm{Co}_{0.2} \mathrm{O}_{2}\right), \quad 6: 2: 2$ $\left(\mathrm{LiNi}_{0.6} \mathrm{Mn}_{0.2} \mathrm{Co}_{0.2} \mathrm{O}_{2}\right)$ and 8:1:1 $\left(\mathrm{LiNi}_{0.8} \mathrm{Mn}_{0.1} \mathrm{Co}_{0.1} \mathrm{O}_{2}\right)$. The question then arises as to which of these compositions is the most favorable one, and if $8: 1: 1$ is technically and commercially feasible (Kim et al., 2018). This shifts the frequently discussed raw material question from cobalt to nickel, especially in the time horizon of 2030 .

In parallel, the handling and recycling of LIB from end-of-life (EoL) vehicles at the end of their service life is proving to be extremely challenging for battery manufacturers and recyclers. However, used batteries also offer economic opportunities. This is particularly true in an environment in which manufacturers of key components of e-mobility are trying to secure their access to raw materials of strategic economic importance in the long term. The materials and elements from LIBs of EVs can be an extremely valuable secondary source. In addition to material recycling, alternative recycling strategies such as reuse, repair and remanufacturing offer the possibility of extending the economically usable life of a battery system and at the same time mitigating the growing demand for resources for the production of energy storage systems.

Assuming a 10 years lifetime in automotive followed by a 10 years lifetime in stationary applications, those batteries have a time delay of 20 years for any recycling effort. In this context, one can ask when would these used batteries will be available for the 
recycling strategies. Additionally, the automotive battery mass market is assumed to begin earliest in 2023 (Sonoc et al., 2015). This market cannot be the recycling driver in such a short run. This means, currently it is vital to discuss the available materials coming from consumer cells and small traction batteries (eg e-bikes, e-scooters, pedelecs and segways). In order to be able to evaluate the feasibility of such reverse supply chains at all, in the first step the potential return volumes from EoL batteries have to be estimated. In addition to the quantity as a function of time, other factors such as development in the battery performances (direct effect on the EoL), battery chemistry in the future as well as reuse and recycling costs have to be taken into consideration. On this basis, various recycling strategies could be predicted in accordance with the European waste regulations.

Taking into account that Li-ion will be the dominating system for a long time, and the battery demand and production capacities will be growing together along with the anticipated development of Ni-rich cathodes for Li-ion cells, we reduced the prominent questions to the following; First, the expected NMC compositions (until 2030) will be discussed including performance aspects such as cycling aging, safety and cost. Secondly, the question of raw material availability is explored, taking the competition with the steel industry into account. Lastly, it is discussed whether the various strategies for a circular economy (recycle, reuse, repair, remanufacture) can possibly reduce the market stress and contribute to raw material availability.

\section{EVALUATION AND PROGNOSIS OF EXPERTS' SURVEY}

The methodology consists of two-step analysis. Firstly, we perform an extensive literature study of the market shares of EV batteries, their chemistry and expected lifetime. The findings are further supported with expert opinions in order to predict the possible developments in the future. Secondly, we perform a criteria-based prognosis for the realistic scenarios of battery development until 2030. The complete survey consisted of 13 questions focused on battery lifetime, second life and future battery developments.

The literature study complements the finding from the experts and helps in verification. As a first step thematically matched experts (battery R\&D scientists, recyclers, manufacturers, raw material experts, consultants etc.) were identified. We have then defined the necessary questions and scenarios in order to adequately evaluate the survey and to gain a deeper understanding of today's challenges, requirements and prospective expectations. Elicitation interviews took place in april 2020 by mailing them a questionnaire (see Supplementary Material).

\section{Experts' Opinion on the Evolution of Li-Ion Battery Cathode Chemistry}

Due to the various stakeholders' involvement, from the fields of producer-customer, raw material suppliers and recycling market, a target-oriented interdisciplinary survey must be conducted to identify future battery technologies and business developments.
Collectively, there is an estimation of global demand of 1,200 GWh battery capacity in the year 2030, which is projected to increase to $3.500 \mathrm{GWh}$ by 2050 (Dolega, 2019). Zubi et al. reported around 1.5 Million of EV will be sold worldwide in 2020 and the LIB demand is expected to reach 240GWh in 2030 (including EV, PHEV and HEV) (Zubi et al., 2018). The rapid growth may lead to temporary shortages of lithium, nickel and cobalt under certain circumstances. Currently the primary stateof-the-art automotive Li-ion chemistries are $\mathrm{LiNi}_{0.8} \mathrm{Co}_{0.15} \mathrm{Al}_{0.05} \mathrm{O}_{2}$ (NCA), spinel $\mathrm{LiMn}_{2} \mathrm{O}_{4}$ (LMO), olivine $\mathrm{LiFePO}_{4}$ (LFP), and layered $\mathrm{LiNi}_{1-x-y} \mathrm{Mn}_{y} \mathrm{Co}_{z} \mathrm{O}_{2}$ (NMC). Among these chemistries, NMC is assumed to have $60 \%$ of market share in the near future (Vaalma et al., 2018).

With reference to this large market share, this paper focuses on NMC chemistry evolution until 2030. A market report of Avicenne Energy (Pillot, 2017) on different NMC chemistries (NMC 811, NMC 622, etc.) for 2020 was used as reference. Also, we asked the experts to predict the expected changes in these chemistries until 2030, if a technologically progressive development is assumed (Figure 1). This progressive development can be realized if all the primary challenges (stable raw material prices, reaching higher energy density and capacity, improved safety and design) are overcome and the battery life cycle is technologically advanced.

NMC cathodes are also particularly robust and more durable than the NCA cathodes. Most EV manufacturers have already presented their near future plans on NMC cathode material. Batteries with Ni-Mn-Co ratio of 1:1:1 (NMC 111) are currently widely used (45\% market share), but alternative ratios with NMC 532 and NMC 622 already exist. Some experts assume that in the future NMC 811 will have the highest market share compared to other ratios. In order to estimate the realistic market shares of different NMC chemistries, we have defined six important key characteristics for EV batteries:

- Raw material prices

- High energy density

- High capacity

- increase of temperature tolerance

- Stability (Safety)

- Reduction of battery weight

As a first step we asked experts to order these characteristics according to their influence on battery design and chemistry. Most of the experts agreed that the increasing raw material prices has the highest influence factor on the decision of battery chemistry. The resulting order of influence factors is shown in Figure 2A.

Increase in raw material costs has a direct impact on the cost of the battery and it is highly predictable that it can play an important role during the development of new battery chemistry. Higher nickel content brings higher capacity and energy content. For example, NMC 111 exhibits $160 \mathrm{mAh} \mathrm{g}^{-1}$ of a specific capacity where this value reaches to more than $200 \mathrm{mAh} \mathrm{g}^{-1}$ for NMC-811 (Schmuch et al., 2018). However, Nirich batteries become less stable and consequently show shorter cycle life. Furthermore, production is usually more expensive due 


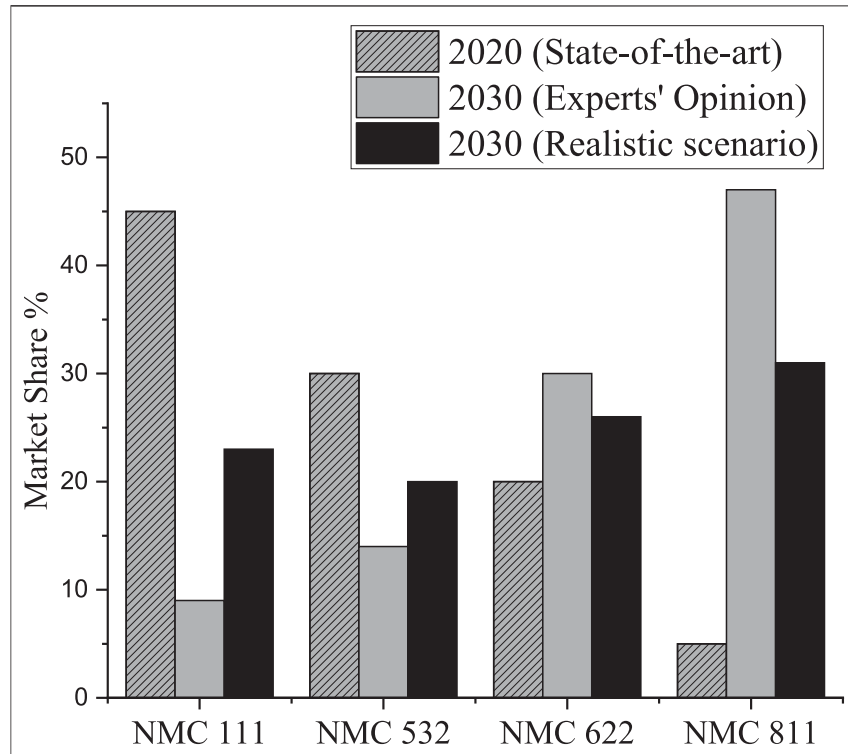

FIGURE 1 | Evolution of NMC Chemistry from 2020 to 2030 and the values according to realistic scenario calculations.

to need of extra additives and safety concerns (temperature tolerance, stability). Last but not least, the weight of the battery has also a direct impact on the performance of the EVs. Lighter battery results with lighter EV with extended driving range.

We gave certain statements and requested the experts' viewpoint (Table 1). Not every expert answered every question and some of them stayed "undecided." Specifically, we asked about the probability of achieving a battery with high performance and better safety with low cost in 2030 .

Given the disagreement of the experts on raw material prices, we further analyze the potential of alternative end-of-life strategies to reduce fluctuations of raw material prices. For the rest of the statements, most of the experts believed that there will be a success for higher capacity, higher energy density, higher temperature tolerance, higher safety and lighter battery packs. The table above also summarizes the expected developments for Ni-rich cathodes.

\section{Experts' Opinion on calendar lifetime of batteries}

Most batteries used in EVs currently have a minimum warranty of 8-year (Neubauer and Pesaran, 2011; Skeete et al., 2020). According to answers of 24 experts, the average life of an EV battery in 2030 is estimated as 12.2 years assuming the development is technically progressive (Figure 2B). Based on many studies, the SoH of an EV battery is reduced to $80 \%$ after 8-10 years. External factors such as operating temperature, overcharge/discharge, high charge/discharge rates and improper charge/discharge cycles can negatively affect the SoH (Barré et al., 2013). The SoH indicates the condition of the battery system and characterizes its ability to meet the specified

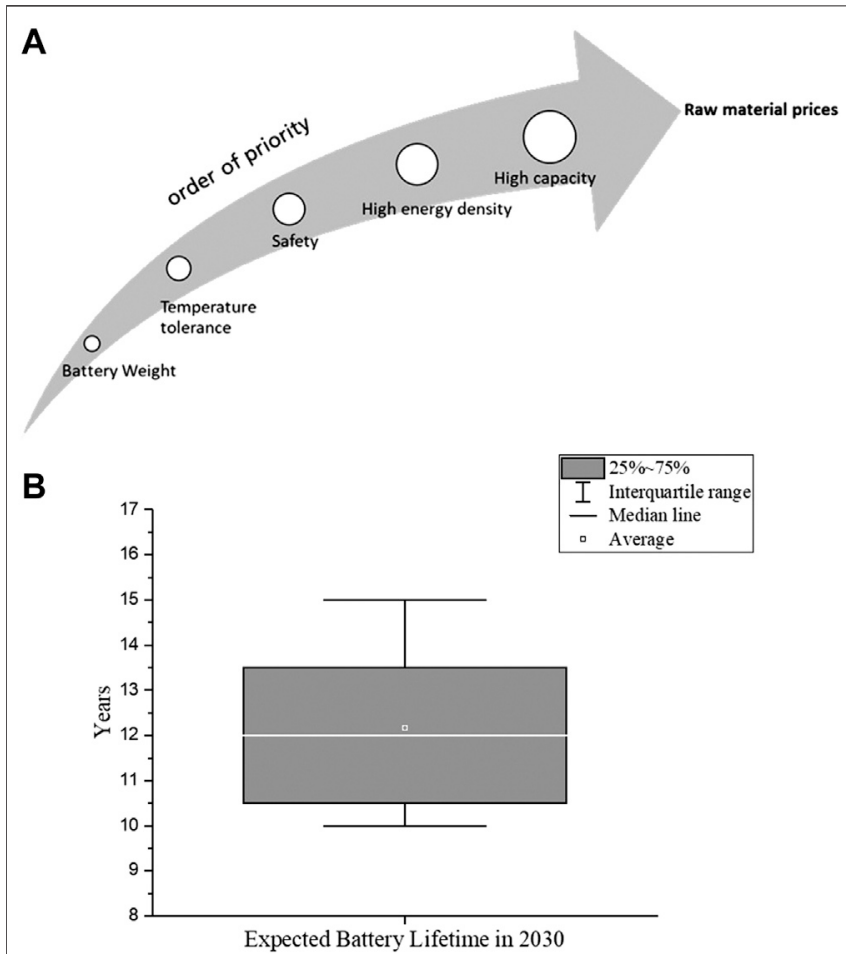

FIGURE 2 | (A) Impact of influence factors on battery chemistry developments (B) Expected battery lifetime in 2030 if the important influence factors are improved.

performance specifications. The specification of $\mathrm{SoH}$ is related to the performance values of a new battery system. Hereby we first asked experts to rank the influence of the individual factors on the life of a battery. After evaluation of expert answers, the following order was established: Temperature $>$ SoC $>$ range $>$ C-Rate Cycle number.

Brief explanations of these factors and their impact the $\mathrm{SoH}$ and consequently the battery lifetime are given in Supplementary Material.

Thereby the operating temperature has a much greater effect on the $\mathrm{SoH}$ than the SoC range, $\mathrm{C}$ rate and number of cycles. In this case, it should be noted that for future developments, the battery materials must be more resistant to fluctuations in the operating temperature. In addition, the battery must be able to operate in a wider SoC range. According to the order of the influencing factors, weighting impact numbers were distributed from 1 (lowest impact) to 4 (highest impact).

Following the assignment of weightage to the influencing factors, the experts were asked to estimate the development potential of the respective factors until 2030. According to the majority of the experts, the higher C-rates capability and achieving high cycle numbers are estimated to have a high development potential, whereas the higher temperature resistance and broader SoC rate can still be a challenge (Table 2). A "score" is specified for each of the influencing factors in the table: 
Table 1 | Statements on battery developments and expert answers.

\begin{tabular}{|c|c|c|c|c|}
\hline Development until 2030: & Disagreed & Agreed & Undecided & Favoring Ni-rich Cathodes? \\
\hline Raw material prices for battery material will rise & 8 & 8 & 9 & YES \\
\hline The energy density of Battery Systems will increase & 0 & 22 & 3 & YES \\
\hline The weight of Battery Systems is decrease & 5 & 16 & 4 & YES \\
\hline The temperature tolerance of Battery Systems will increase & 3 & 15 & 7 & NO \\
\hline The stability of Battery Systems will increase & 1 & 16 & 8 & $\mathrm{NO}$ \\
\hline The capacity of Battery Systems is increase & 4 & 20 & 1 & YES \\
\hline
\end{tabular}

Table 2 | Battery life influencing factors and their development forecast.

Influencing factors

\section{Development potential of Score the influencing factors until $\mathbf{2 0 3 0}$}

Achieving higher cycle numbers

Increase in C-Rates

Broader SoC range

Increase of the temperature resistance

- Low Potential = 0

- Medium Potential $=0.5$

- High Potential = 1

These scores together with impact numbers are used later in Realistic Scenarios of Future Developments in Battery Technology in order to calculate a realistic battery life expectancy.

\section{Realistic Scenarios of Future Developments in Battery Technology}

This section presents the individual results of the expert survey and the forecasting for the battery life and chemistry. Detailed calculations of realistic scenarios are given in the Supplementary Material Sections 1-3.

Taking into account the resulting weighting and the expected development of the influencing factors described in the previous section were used to calculate Realistic Development Potential (RDP) \%. According to the described procedure (Supplementary Material 1), a RDP \% is obtained as 65\%. The difference between the progressive (Experts' opinion) and conservative (state-of-theart) scenario is equal to 4.2 years. In this case, an expected life of lithium-ion battery systems in 2030 according to a calculated realistic is rounded to $\mathbf{1 1}$ years.

As Table 1 lists all relevant influencing factors and shows the estimations of the 25 experts for the future development, another $\mathrm{RDP} \%$ for the battery chemistry can be calculated as $62.6 \%$ (Supplementary Material 1). The dominating answers are marked bold and the answers with "undecided" were neglected. Accordingly, realistic market shares can be seen in the last row of Table 3 .

A realistic calculation was indispensable for analyzing the coherence of the answers. The answers obtained from experts had to be examined in terms of inner logic, consistency and plausibility. As a result, the realistic market share of NMC 111 can be forecasted still higher than the experts' opinion (Figure 1 and Table 5).
Table 3 | NMC Chemistry market share (\%) according to literature, experts and calculation.

\begin{tabular}{lcccl} 
NMC 111 & NMC 532 & NMC 622 & NMC 811 & Origin of the value \\
\hline 45 & 30 & 20 & 5 & Literature ${ }^{[34]}$ \\
9 & 14 & 30 & 47 & Experts \\
-36 & -16 & 10 & 42 & Difference \\
$\mathbf{2 2 . 5}$ & $\mathbf{2 0}$ & $\mathbf{2 6 . 3}$ & $\mathbf{3 1 . 2}$ & Realistic market share
\end{tabular}

When we interpreted these numbers, it must be noted that, the dominant NMC lithium-ion cells with a simultaneous increase in the nickel content is already in progress today. Without the trend toward lithium-ion cells with reduced cobalt content, the demand for cobalt for global e-mobility would still be considerably high in the medium and long term.

\section{RAW MATERIAL SITUATION AND POTENTIAL SHORTAGES}

LIBs consist of several raw materials that are associated with medium or high supply risk (Helbig et al., 2018). As this work focusses on cell chemistries based on nickel-manganese-cobalt (NMC) cathodes, these materials have to be analyzed in detail. The same applies to lithium as it is considered an "important, substantial and probably critical metal" as well (Simon et al., 2015). Instead of a detailed material criticality assessment, a qualitative discussion of relevant factors concerning the four mentioned raw materials is conducted. Therefore, some generally acknowledged indicators (Benjamin Achzet, 2013) or describing the supply risk are discussed but not evaluated in detail. Additionally, the expected change in cell chemistry of LIBs is assessed in terms of its effect on the future sustainable supply of battery materials.

Recent developments in lithium ion technology aim on nickel rich cathodes. Starting from equal shares of nickel, manganese and cobalt (NMC 111) in the first generations of NMC-batteries, the share of nickel is increased while reducing the ones of manganese and cobalt. The stepwise progression went to the second generation of NMC cathodes with material shares of $50 \%$ nickel, 30\% manganese, $20 \%$ cobalt (NMC 532) and $60 \%$ nickel, $20 \%$ manganese, $20 \%$ cobalt respectively (NMC 622) (Study on the review of the list of critical raw materials: Final report, 2017). The third generation, which is expected to become predominant 
Table 4 | Material demand scenarios.

\begin{tabular}{|c|c|c|c|c|}
\hline & Scope & Name of Scenario & Abbr. & Color Scheme \\
\hline \multirow[t]{6}{*}{ Material Demands in $\mathrm{t}=2020$ [metric t] } & Only Battery & Battery: Scenario 100\% NMC 111 & $1 x$ & - \\
\hline & & Battery: Scenario 100\% NMC 811 & $1 y$ & - \\
\hline & & Battery: Scenario Realistic Mix & $1 z$ & - \\
\hline & All Applications & All: Scenario 100\% NMC 111 & $2 x$ & - \\
\hline & & All: Scenario 100\% NMC 811 & $2 y$ & - \\
\hline & & All: Scenario Realistic Mix & $2 z$ & - \\
\hline \multicolumn{2}{|c|}{ Material Supply (annual mining rate) [metric t] } & & & - \\
\hline
\end{tabular}

in the mobility sector within the next years, utilizes cathodes comprised of $80 \%$ nickel, $10 \%$ manganese and $10 \%$ cobalt (NMC 811) (McKinsey and Company, 2018). Beside an increase in battery capacity, the decrease of the manganese and cobalt shares in battery cathodes is often associated with an easing of the material supply situation for LIBs (Olivetti et al., 2017; Schmuch et al., 2018).

This is mainly due to the critical conditions of the cobalt supply chain. In 2018 around $70 \%$ of the cobalt mine production took place in the Democratic Republic of Congo. Not only the fact of the extreme concentration of the world's production but also the critical situation concerning the governance and living conditions of the Democratic Republic of Congo and other cobalt producing countries (eg China, Russia, and Madagascar) results in a high rating of cobalt's supply risk. This statement is based on the interpretation of indicators provided by the World Bank Group (world governance indicators-voice and accountability, -political stability and absence of violence, -control of corruption), the United Nations Development Program (Human Development Index) and the Fraser Institute (Policy Perception Index) (United Nations Development Program).

Manganese is rated with a medium criticality, mainly due to its above-average country concentration. While being far afield from the geographical concentration of mining operations for cobalt, the potential risk for cuts in the supply chain exists if political and/or civil commotions occur (Fortier et al., 2018). The accompanied political risk is also assessed as slightly above average (United Nations Development Program). Manganese has no promising substitutes for most of its main applications, which increases its supply risk significantly (Graedel et al., 2015). Manganese is abundant in Earth's crust, however only around $4.5 \%$ of the world's manganese resources are currently classified as reserves (Fortier et al., 2018). Moreover, it is currently recyclable and future technologies are not expected to contribute to a significant increase in demand prospectively (Graedel et al., 2011). Also, the fact that manganese is mainly mined as a host metal and not as a by-product, lowers its respective supply risk (Nassar et al., 2015).

Based on generally acknowledged indicators for evaluating the supply risk of materials, nickel receives the lowest rating of the four considered materials (Graedel et al., 2015). The country concentration is assessed as medium (Fortier et al., 2018) as well as the related political risk (except for the human development index, which receives a more critical rating. Same as for
Table $\mathbf{5}$ | Executive summary of the survey.

Number of Total Experts 25

Valid Answers for Battery Life

24

\begin{tabular}{cc}
\multicolumn{2}{c}{ Valid Answers for NMC Evolution } \\
\hline$\frac{25}{\text { Experts' Opinion }}$ \\
\hline 12.2 & $\frac{\text { Realistic Scenario }}{11}$
\end{tabular}

Market Share \%

NMC 111

NMC 532

NMC 622

NMC 811
9

14

30

47
22.5

20

26.3

31.2 manganese, recycling pathways for nickel are widely established. Furthermore, the expected increase in demand for future technologies is rather low, compared to the demand for current conventional applications (especially steel production) (Marscheider-Weidemann et al., 2016; Schmuch et al., 2018).

Same as for cobalt, lithium is characterized by a noticeable concentration of production. Australia $(\sim 61 \%)$ and Chile $(\sim 18 \%)$ dominate the world's supply (Fortier et al., 2018). However, stable governance conditions in most lithium mining countries compared to the ones of cobalt mining countries result in a lower political- and thus supply risk. This is again except for the Human Development Index, which is rated as critical (United Nations Development Program). Although not established on a large scale, at least some companies are able to recycle lithium from EoL products and improvement is expected in the future. The increase in demand for future technologies compared to the current mining output is rated as very critical (Fortier et al., 2018; Marscheider-Weidemann et al., 2016). This is mainly due to the expected market penetration of LIBs (Marscheider-Weidemann et al., 2016).

In order to estimate the consequences of a change in cell chemistry on the availability of the four assessed raw materials, a scenario analysis is conducted. The six scenarios represent different assumptions concerning material demand in year 2030. Scenarios $1 x, 1 y$ and $1 z$ focus on the demand solely caused by increasing demand for LIBs, while scenarios $2 x, 2 y$ and $2 \mathrm{z}$ include the total demand for batteries and other applications. This is done in order to give an impression about the impact of increasing battery demand on the commodity market and the market power of competitors for available 


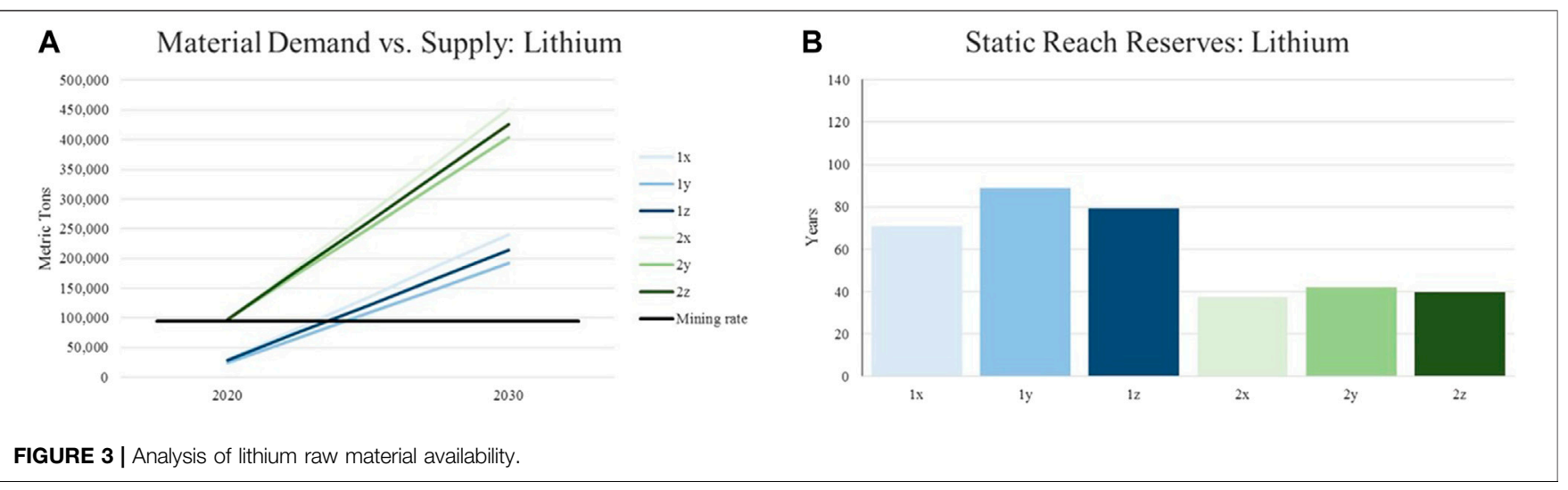

reserves. Also, this analysis indicates necessary increases in mining capacity. For each scope (only battery and all applications) there is one conservative scenario (100\% NMC 111 in 2030: $1 x \& 2 x$ ), one progressive scenario (100\% NMC 811 in 2030: $1 y \& 2 y$ ) and one realistic scenario which is based on the results of the expert interview introduced in section 2.3.2 ( $1 z$ and $2 z$ ). The individual scenarios are depicted in Table 1. Each scenario is compared to the current mining rate in order to illustrate potential gaps between supply and demand. Due to reasons of simplification, it is assumed, that the annual mining rates and thus the material supply remains constant. Hence, this juxtaposition is intended to give a first glimpse on the magnitude of future demands in relation to current supply.

The future material demand for LIBs are calculated by considering the material inputs per $\mathrm{kWh}$ for each cell chemistry, the assumed shares of cell chemistries and the predicted battery capacity for automotive application in 2030 . The material inputs per kWh of NMC 111, NMC 622 and NMC 811 are based on Olivetti et al. (2017), while the ones for NMC 532 are based on own assumptions (Olivetti et al., 2017). Further calculations are based on the average of predicted battery capacity from Campagnol et al. and Roland Berger GmbH (ref. Table 6). The two literatures have concordant predictions of future demands for LIBs, which is why the forecast of Zubi et al. is neglected in this work (Zubi et al., 2018).

The demand in the scenarios with the scope of including all applications of the respective material are composed of the projected demand for Li-Ion batteries in 2030, the current amounts used for the most prominent applications (Fortier et al., 2018) as well as the predicted demand for future technologies in 2035 (Bernhart, 2019). Hence, it is assumed, that the demand induced by the current main uses remain constant to today's level.

For illustrating potential shortages in supply, the annual material demand represented by the introduced scenarios are put in relation with currently identified reserves of the assessed materials. This is done in order to calculate the reach of material supply in years. Same as for the constant material supply, the world's reserves are expected to remain the same until 2030. Although this results in a certain inaccuracy, historic data from the United States Geological Survey concerning the reserves of various raw materials show that such a hypothesis is reasonable.
Table 6 | Literature - Li-lon battery demand in 2030

\begin{tabular}{|c|c|c|c|c|}
\hline \multirow[t]{2}{*}{ Literature Source } & \multirow[t]{2}{*}{ Name of Dataset } & 2020 & 2025 & 2030 \\
\hline & & \multicolumn{3}{|c|}{$\begin{array}{l}\text { Battery Capacity } \\
\text { [GWh] }\end{array}$} \\
\hline $\begin{array}{l}\text { Campagnol et al. } \\
(2018)\end{array}$ & $\begin{array}{l}\text { Battery Capacity for Electric } \\
\text { Mobility }\end{array}$ & - & 735 & 1890 \\
\hline Roland Berger (2018) & Automotive Battery Cell Demand & 213 & 794 & 1559 \\
\hline Average & & 213 & $\sim 765$ & $\sim 1725$ \\
\hline
\end{tabular}

The following charts depict the described evaluation for the materials focused in this article (lithium, nickel, manganese, cobalt). The legend with the color scheme for the individual graphs can be found in Figure 3 and Table 4.

It can be observed, that the lithium demand for traction batteries alone will surpass the current supply in each scenario before 2025. Although this seems very critical it needs to be stated, that lithium mining capacities are currently not utilized at full load. However, even by doubling the annual lithium supply, demands for Li-Ion batteries in the realistic scenario will exceed the available amount. In order to meet the total demands for lithium, the production capacity needs to be increased fourfold. Li-ion batteries account for nearly half of the world's demand for lithium. The static reach of lithium increases slightly due to lower material inputs per $\mathrm{kWh}$ in batteries with nickel-rich cathodes. However, the effect on the scope including all applications can be scored as low Figure 4.

Compared to the global demand, the nickel demand for LIBs are currently insignificant. However, increasing demands alongside with higher nickel contents in future battery systems will raise the share on the global demand from around $4 \%$ in 2020 to $34 \%$ (scenario $100 \%$ NMC 811 ) and $30 \%$ (realistic scenario) respectively. This illustrates the increasing market power of cathode- and/or battery manufacturers. Excessive current supply in the early twenties indicates the possibility of shortage in material availability and price increase. The change in battery chemistry has huge influence on the static reach of the nickel reserves. By supposing a complete market penetration of NMC $811(1 y)$ the static reach is cut in half compared to the conservative scenario $(1 x)$. Including the demands of the current main 

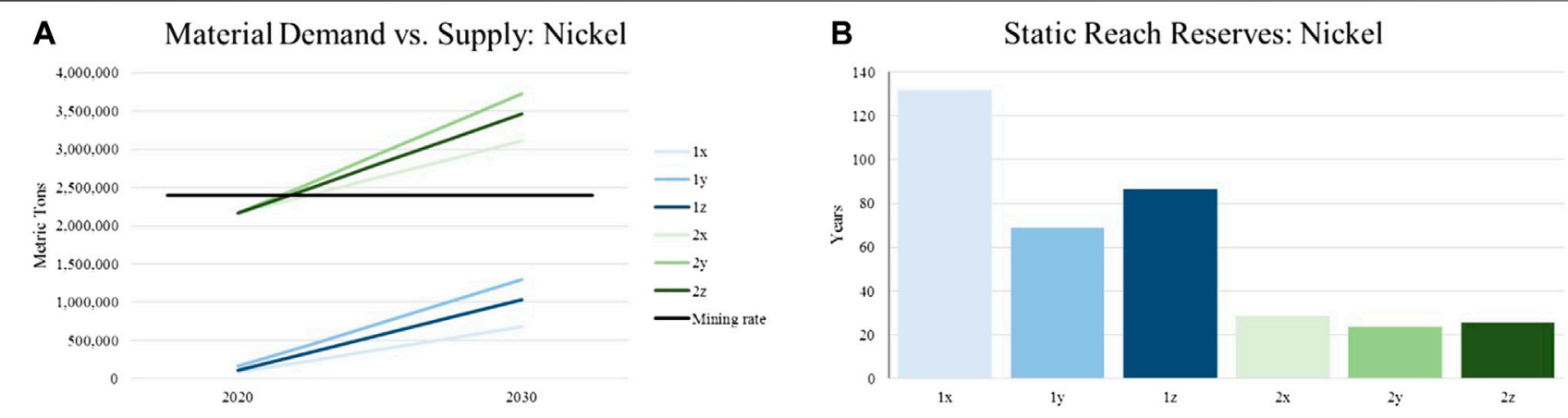

FIGURE 4 | Analysis of nickel raw material availability.

applications and future technologies with LIBs, the static reach of the nickel reserves approaches critical values of around 20 years Figure 5.

The demand for manganese in LIBs is insignificant compared to the global demand of all applications (mainly metallurgy). This pertains to each analyzed scenario. The change in battery chemistry has nearly no impact on the supply-demand ratio. Respectively, the static reach of manganese reserves in the scenarios with focus on battery demands $(1 x, 1 y, 1 z)$ is higher than any strategic planning horizon (notice the inconsistent $y$-axis). Although battery demand does not have a measurable effect, the static reach is decreased to around 40 years by incorporating all applications of manganese $(2 x, 2 y, 2 z)$. Hence, supposing there are shortfalls in manganese supply, the battery industry is in competition with strong market participants Figure 6.

As expected, the availability of cobalt is scored to be the most critical. Even by assuming the complete market penetration of NMC 811, the cobalt demand for traction batteries only surpasses the current supply $(1 y)$. The total demand for cobalt in the realistic scenario equals around 3.6 times the current mining rate $(2 z)$. By assuming a conservative scenario and thus NMC 111 to stay the predominant cathode, the demand is equivalent to 5.7 times the current supply $(2 x)$. By lowering the cobalt content in battery systems, the static reach of cobalt reserves can be extended from 8 $(2 x)$ to $22(2 y)$ years. The static reach in the realistic scenario amounts to 13 years which is assessed as highly critical.

As recycling bears the potential of easing the presented supply situation, the following section discusses the state-of-the-art recycling routes for LIBs.

\section{CURRENT RECYCLING TECHNOLOGIES AND THEIR CONTRIBUTION TO REGAIN CRITICAL RAW MATERIALS}

Recycling is a key element within the circular economy, to keep materials in a closed loop system and to reduce the demand for primary raw materials in production, which in turn reduces the supply risk of critical raw materials. The increasing number of LIBs collected from EVs at their EoL raises the need for recycling. Recycling of LIBs typically includes pre-treatment processes, pyrometallurgical and or hydrometallurgical processes (Mossali et al., 2020).

\section{Pre-Treatment Processes}

Pre-treatment processes comprise various activities before either hydrometallurgical or pyrometallurgical processes or mixtures of both are applied to recycle LIBs (Li et al., 2018; VelázquezMartínez et al., 2019; Mossali et al., 2020). Main objectives according to 55 are improvement of recovery rate, management of safety issues, reduction of scrap volumes and energy consumption and enrichment of the metallic fraction.

As a prerequisite for an efficient recycling and due to the increasing variety of LIBs, they are first sorted and classified regarding battery type and battery chemistry (Melin, 2019). To prevent risks like short circuiting or spontaneous combustion during handling and manipulation, LIBs are then discharged (Hanisch et al., 2015; Li and et al., 2018; Mossali et al., 2020). This is usually done by immersing the LIB in salt solutions (Wang et al., 2017; Zheng et al., 2018; Mossali et al., 2020). 60 describe alternatives like connecting the LIBs to resistors to collect the residual energy or stimulating a controlled short circuit (Hanisch et al., 2015; Mossali et al., 2020).

For the recycling of battery systems, these are generally completely disassembled for processing to enable a material recovery of individual cells and to decrease the volume of the product to be treated (Mossali et al., 2020). Because of the high variety of LIBs, this is usually done manually, however research is focusing on possibilities to automate this process to reduce time and costs (Melin, 2019; Mossali et al., 2020). The cells are further dismantled manually to separate cathode, anode and other components or by mechanical separation (Zheng et al., 2018). Binder materials such as polyvinylidene fluoride (PVDF) or polytetrafluoroethylene (PTFE) make it difficult to separate the cathode material from the substrate (aluminum foil). There are different methods to solve this issue, eg ultrasonic-assisted separation, thermal treatment or a solvent dissolution method (Gaines, 2018; Melin, 2019). Besides thermal and chemical pretreatments, mechanical and physical pre-treatments are the most used technique at industrial level, which allows to segregate valuable materials and to reduce scrap volumes (Mossali et al., 2020). Mechanical pre-treatments are based on differences in the physical properties and do not alter the cell chemistry 

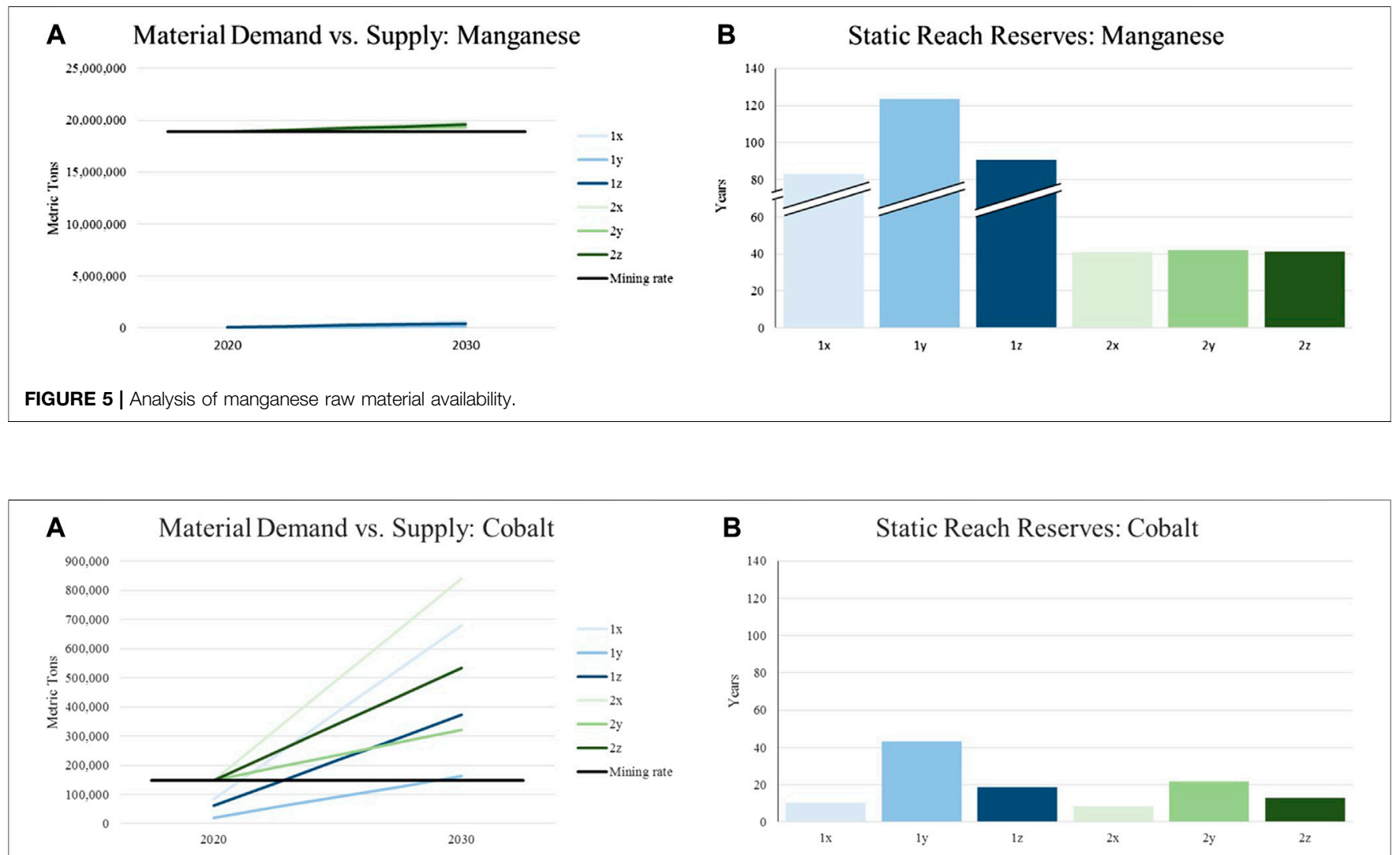

FIGURE 6 | Analysis of cobalt raw material availability.

(Velázquez-Martínez et al., 2019). Crushing, shredding and grinding is used to segregate current collector foils and organic materials from the active leachable powder. The increased surface enables a more efficient dissolution of metals during acid leaching in the following hydrometallurgical process (Hanisch et al., 2015; Mossali et al., 2020). However, mechanical pre-treatments like shredding mix up the anode and cathode materials at the start of the process, which makes it more complex in the downstream processes (Harper et al., 2019).

\section{Pyrometallurgical Recycling}

Pyrometallurgical processes are the most mature battery recycling technology, even if this process was not intended for use in recycling of spent LIBs during their initial design (Baltac and Slater, 2019; Fan et al., 2020). The simple operation and the ability to recycle different battery chemistries simultaneously are one of the main advantages of this recycling scheme (Baltac and Slater, 2019; Fan et al., 2020). However, according to Dunn et al. using pyrometallurgy recycling for LMO, LFP and NMC batteries does not reduce green house gases, since the emissions from primary production of their virgin materials are lower (Joulié et al., 2014).

For pyrometallurgical recycling, LIBs are dismantled either to module or cell level, without the need for a prior passivation step. They are fed to a high-temperature shaft furnace, together with a slag forming agent (Gaines, 2014; Harper $t$ al., 2019) Within the high-temperature furnaces where the batteries are placed, redox reactions are activated to smelt and purify valuable metals, which are reduced and recovered in the form of alloys (Lv et al., 2018; Zheng et al., 2018; Velázquez-Martínez et al., 2019). During the process, the heat of burning materials (eg electrolytes, plastics, wires) can be re-used to reduce the energy consumption (Gaines, 2014; Gaines, 2018; Baltac and Slater, 2019; Harper et al., 2019). Output of the pyrometallurgical process are a metallic alloy fraction, slag and gases (Harper et al., 2019). High temperature facilitates oxidation and reduction reactions resulting in a mixed metal alloy containing copper, cobalt, nickel and iron (Gaines, 2018; Baltac and Slater, 2019; Harper et al., 2019; Fan et al., 2020; Mossali et al., 2020). The alloy can be separated through hydrometallurgical processes (Harper et al., 2019). The resulting furnace slag consists of ashes and burnt components, primarily containing aluminum, lithium, silicon, calcium, iron and manganese, which was present in the cathode material (Gaines, 2014; Baltac and Slater, 2019; Harper et al., 2019). In general, the aluminum and lithium in the slag is not recovered, since it is not economically viable (Gaines, 2018; Mossali et al., 2020). Instead, the slag can be reused eg as cement additive (Hanisch et al., 2012; Gaines, 2018). For a comprehensive description of recycling processes regarding lithium recovery including method, efficiency and quality (Shin et al., 2005). To avoid the release of potentially toxic by- 
products, gas clean-up steps are necessary (Gaines, 2014). Despite disadvantages of the pyrometallurgical process, like high capital costs, production of toxic gases, high-energy consumption and limited number of reclaimed materials, it remains a frequently used, economical process for the extraction of high-value transition metals as cobalt and nickel (Gaines, 2014; Joulié et al., 2014; Chen et al., 2015; Harper et al., 2019; Mossali et al., 2020).

\section{Hydrometallurgical Recycling}

Hydrometallurgical processes are used after pre-treatments, in which battery packs are dismantled and cells further fragmented, eg by shredding (Baltac and Slater, 2019). Leaching is one of the key processes in which the ions are dissolved out of a solid like the active cathodic powder by using acids, resulting in a mixture of ionic species in solution (Gaines, 2018; Lv et al., 2018; Yao et al., 2018; Baltac and Slater, 2019; Harper et al., 2019; Mossali et al., 2020). Main operating parameters are temperature, acid and reducing agent concentration and species, reaction time and solid/liquid ratio (Li et al., 2018; Harper et al., 2019; Mossali et al., 2020). The metals in the solution can be recovered in high rates using a series of chemical methods like precipitation, solvent extraction and electrolytic deposition resulting in separated elements, which can be eg used to produce new cathode material (Gaines, 2018; Yao et al., 2018; Baltac and Slater, 2019). Due to their similar properties, cobalt and nickel ions are difficult to separate from each other (Gaines, 2018).

In general, the main advantages of hydrometallurgical processes compared with pyrometallurgical processes are higher recovery efficiency of valuable metals, especially $\mathrm{Li}$, lower energy consumption, less production of toxic gases and lower capital costs (Lv et al., 2018; Fan et al., 2020; Mossali et al., 2020). Main drawbacks of using hydrometallurgical processes for LIB recycling are high dependency on pre-treatments and used technologies, emissions associated with the used chemicals and difficulty to process different battery chemistries and battery at once (Baltac and Slater, 2019; Mossali et al., 2020). This is due to the fact that each recycling sequence has to be optimized for a certain battery chemistry, to ensure high recovery of materials and favourable economics (Baltac and Slater, 2019). While the use of strong acids is connected with possible health issues and contamination of the environment, and also increases process costs and complexity, current studies propose the use of biodegradable organic acids (Gaines, 2018; Harper et al., 2019; Mossali et al., 2020).

\section{Direct recycling}

Direct, mechanical or physical recycling processes are a new recycling technology, which is still under development and are not yet used on an industrial scale (Baltac and Slater, 2019; Harper et al., 2019). Without using thermal or chemical energy, the recycling process focuses on reusing components or materials in new batteries, e.g. by the separation of components from the active material powder of shredded cells ("black mass") (Gaines, 2018; Shi et al., 2018; Harper et al., 2019). Other forms of direct recycling comprise e.g. the use of supercritical $\mathrm{CO}_{2}$ to extract the electrolyte from battery cells (Mayyas et al., 2019) or the recovery of components like casing and wiring for further processing (Baltac and Slater, 2019).

It is important to highlight, that the recycling processes described above are not just alternatives to each other, but can be used in different combinations and with multiple variations in each design (Managing End-of-Life Li-ion Batteries: Battery Recycling Technologies: Innovative Technologies for the Recovery and Reuse of Valuable Metals from End-of-Life Lithium-ion Batteries, 2020). Due to the complex structure of LIBs, recycling processes were designed with the aim to recover different components (Fan et al., 2020). Generally, hydrometallurgy processes are used after the pyrometallurgy process to recover metals like Co. or Ni from the alloy. More than $90 \% \mathrm{Ni}$ and Co. are recoverable from the molten alloy, for $\mathrm{Cu}$ the recovery rate is lower and $\mathrm{Li}$ and $\mathrm{Al}$ are part of the furnace slag (Fan et al., 2020; Managing End-of-Life Li-ion Batteries: Battery Recycling Technologies: Innovative Technologies for the Recovery and Reuse of Valuable Metals from End-of-Life Lithium-ion Batteries, 2020). A cost-intensive recovery of about $50-60 \%$ of $\mathrm{Li}$ is possible. Hydrometallurgical recycling allows a recovery rate of around 95\% regarding $\mathrm{Ni}$ and Co. as salts, while $\mathrm{Cu}$ can be recovered up to $100 \%$ and $\mathrm{Li}$ by around $90 \%$. Other components are recoverable by up to $80 \%$. To achieve these high rates, the leaching processes are usually tailored for specific battery chemistries and extensive pre-treatment processes are necessary. In the future, hydrometallurgical recycling processes require an efficient and more rapid removal of impurities, to increase the purity of the recovered materials (Fan et al., 2020; Managing End-of-Life Li-ion Batteries: Battery Recycling Technologies: Innovative Technologies for the Recovery and Reuse of Valuable Metals from End-of-Life Lithium-ion Batteries, 2020).

\section{CONCLUSION}

An executive summary of the survey and this study are collected in Table 5. The investigated scenarios of this paper demonstrate a strong market growth in the e-mobility sector. As a result, a rapid increase in LIB production capacities is foreseeable. It is evident that no competitive alternatives to Li-ion technology will arise until 2030 regarding commercialization and mass production. Hence, a significant growth in supply for their key elements (Li, Ni and Co.) is required. As a consequence of the extremely dynamic development of e-mobility, which nowadays includes e-bikes and e-scooters with shorter lifetimes, the raw material demand will tremendously accelerate. Estimations beyond 2030 are subject to high uncertainty due to the potential market penetration of innovative technologies that are currently under research (eg solidstate Lithium-Ion and/or sodium-based batteries).

The results of this paper show that the annual demand for global e-mobility by 2030 will boost the battery production to about 1725 GWh (LIB) and that Ni will be the dominating raw material. LIBs are now and in the coming years driven by higher nickel contents. Among the various NMC subgroups, NMC 111 has currently the highest demand. The present situation concerning battery demand and market shares of the 
respective cell chemistries corresponds to a yearly nickel demand of $4 \%$ of the annual global mining production. In the progressive scenario in which NMC cathode demand is solely met by NMC 811 chemistries, the demand for nickel in year 2030 would increase to $34 \%$ of the current mining production.

Although NMC 111 may still have a notable market share in the near future, the trend toward NMC and NCA battery cells with a high nickel and low cobalt content is clear and will be responsible for an accelerated depletion of nickel reserves by 2050 . However, further research incorporating dynamic supply is recommended. Additionally, a battery grade nickel production requires a specific supply chain, meaning not all nickel resources are feasible for LIBs production. Taking into account that remarkable LIB recycling will take place beyond 2030, since enough cells must be present and second life is envisaged before recycling, potential shortages and tremendous cost uncertainties of $\mathrm{Ni}$ are the consequences. This makes the parallel search for alternative Ni-free battery technologies indispensable from now.

\section{DATA AVAILABILITY STATEMENT}

The original contributions presented in the study are included in the article/Supplementary Material, further inquiries can be directed to the corresponding author.

\section{REFERENCES}

Aurbach, D., Zaban, A., Schechter, A., Ein-Eli, Y., Zinigrad, E., and Markovsky, B. (1995). The study of electrolyte solutions based on ethylene and diethyl carbonates for rechargeable Li batteries: I . Li metal anodes. J. Electrochem. Soc. 142(9), 2873. doi:10.1149/1.2048658

Baeva, S., Shterev, V., Yochev, K., and Hinov, N. (2019). Route optimization for long durability battery life during e-bike cycling. AIP Conf. Proc. 2172(1), 80017. doi:10.1063/1.5133575

Baltac, S., and Slater, S. (2019). Batteries on wheels: the role of battery electric cars in the EU power system and beyond. Cambridge, United Kingdom: Element Energy Ltd.

Barré, A., Deguilhem, B., Grolleau, S., Gérard, M., Suard, F., and Riu, D. (2013). A review on lithium-ion battery ageing mechanisms and estimations for automotive applications. J. Power Sources. 241, 680-689. doi:10.1016/j. jpowsour.2013.05.040

Benjamin Achzet, C. H. (2013). "How to evaluate raw material supply risks-an overview. Resour. Pol. 38(4), 435-447. doi:10.1016/j.resourpol.2013.06.003

Bernhart, W. (2019). Zukunftsmarkt batterie-recycling: verpasst Europa: (wieder) den Anschluss?. Available at: https://www.rolandberger.com/de/Point-of-View/ Zukunftsmarkt-Batterie-Recycling-Verpasst-Europa-(wieder)-den-Anschluss.html (accessed July 18 2020)

Chakrapani, V., Rusli, F., Filler, M. A., and Kohl, P. A. (2012). Silicon nanowire anode: improved battery life with capacity-limited cycling. J. Power Sources. 205, 433-438. doi:10.1016/j.jpowsour.2012.01.061

Chen, X., Chen, Y., Zhou, T., Liu, D., Hu, H., and Fan, S. (2015). Hydrometallurgical recovery of metal values from sulfuric acid leaching liquor of spent lithium-ion batteries. Waste Manag. 38, 349-356. doi:10. 1016/j.wasman.2014.12.023

Dolega, P. (2019). “Gigafactories für Lithium-Ionen-Zellen, Rohstoffbedarfe für die globale Elektromobilität bis 2050”. 2019.

Dominko, R., Fichtner, M., Perraud, S., Tarascon, J.-M., Vegge, T., and Winter, M. (2019). Inventing the batteries of the future. Available at: https://www.energiers2e.com/en/news/inventing-sustainable-batteries-future

\section{AUTHOR CONTRIBUTIONS}

All authors listed have made a substantial, direct, and intellectual contribution to the work and approved it for publication.

\section{FUNDING}

This study was supported by "Ministry of the Environment, Climate Protection and the Energy Sector BadenWürttemberg," with a Grant No 017-100035|B7.R| and managed by the Project Management Agency Karlsruhe (PTKA).

\section{ACKNOWLEDGMENTS}

The authors gratefully acknowledge the contributions of the participating technical experts listed in Supplementary Material.

\section{SUPPLEMENTARY MATERIAL}

The Supplementary Material for this article can be found online at: https://www.frontiersin.org/articles/10.3389/fenrg.2020.594857/ full\#supplementary-material

Fan, E., Li, L., Wang, Z., Lin, J., Huang, Y., Yao, Y., et al. (2020). Sustainable recycling technology for Li-ion batteries and beyond: challenges and future prospects. Chem. Rev. 120, 7020-7063. doi:10.1021/acs.chemrev.9b00535

Fortier, S. M., Hammarstrom, J. H., Ryker, S. J., Day, W. C., and Seal, R. R. (2018). USGS Critical Minerals Review. Mining Eng. 71, 35.

Managing end-of-life Li-ion batteries: battery recycling technologies. in Innovative technologies for the recovery and reuse of valuable metals from end-of-life lithium-ion batteries. Santa Clara, CA

Gaines, L. (2018). Lithium-ion battery recycling processes: research towards a sustainable course. Sustainable Materials and Technologies. 17, e00068. doi:10. 1016/j.susmat.2018.e00068

Gaines, L. (2014). The future of automotive lithium-ion battery recycling: charting a sustainable course. Sustainable Materials and Technologies. 1-2, 2-7. doi:10. 1016/j.susmat.2014.10.001

Graedel, T. E., Allwood, J., Birat, J.-P., Buchert, M., Hagelüken, C., Reck, B. K., et al. (2011). What do we know about metal recycling rates?. J. Ind. Ecol. 15(3), 355-366. doi:10.1111/j.1530-9290.2011.00342.x

Graedel, T. E., Harper, E. M., Nassar, N. T., Nuss, P., and Reck, B. K. (2015). Criticality of metals and metalloids. Proceedings of the National Academy of Sciences of the United States of America. 112(14), 4257-4262. doi:10.1073/pnas. 1500415112

Graedel, T. E., Harper, E. M., Nassar, N. T., and Reck, B. K. (2015). On the materials basis of modern society. Proc. Natl. Acad. Sci. Unit. States Am. 112 (20), 6295-6300. doi:10.1073/pnas.1312752110

Handbuch lithium-ionen-batterien. Berlin: Springer Vieweg, (2013).

Hanisch, C., Haselrieder, W., and Kwade, A. (2012). "Recycling von LithiumIonen-Batterien - das Projekt LithoRec," in Recycling und Rohstoffe. (Neuruppin: TK-Verl.), 691-698.

Hanisch, C., Loellhoeffel, T., Diekmann, J., Markley, K. J., Haselrieder, W., and Kwade, A. (2015). Recycling of lithium-ion batteries: a novel method to separate coating and foil of electrodes. J. Clean. Prod. 108, 301-311. doi:10.1016/j. jclepro.2015.08.026

Harper, G., Sommerville, R., Kendrick, E., Driscoll, L., Slater, P., Stolkin, R., et al. (2019). Recycling lithium-ion batteries from electric vehicles. Nature. 575(7781), 75-86. doi:10.1038/s41586-019-1682-5 
Helbig, C., Bradshaw, A. M., Wietschel, L., Andrea, T., and Tuma, A. (2018). Supply risks associated with lithium-ion battery materials. J. Clean. Prod. 172, 274-286. doi:10.1016/j.jclepro.2017.10.122

Marscheider-Weidemann, F., Langkau, S., Hummen, T., Erdmann, L., Tercero Espinoza, L., Angerer, G., et al. (2016). Rohstoffe für Zukunftstechnologien 2016: Auftragsstudie. Hannover: DERA.

Joulié, M., Laucournet, R., and Billy, E. (2014). Hydrometallurgical process for the recovery of high value metals from spent lithium nickel cobalt aluminum oxide based lithium-ion batteries. J. Power Sources. 247, 551-555. doi:10.1016/j. jpowsour.2013.08.128

Keck, F., Lenzen, M., Vassallo, A., and Li, M. (2019). The impact of battery energy storage for renewable energy power grids in Australia. Energy. 173, 647-657. doi:10.1016/j.energy.2019.02.053

Kim, J., Lee, H., Cha, H., Yoon, M., Park, M., and Cho, J. (2018). Prospect and reality of Ni-rich cathode for commercialization. Adv. Energy Mater. 8 (6), 1702028. doi:10.1002/aenm.201702028

Kumar, M., Yoo, J., and Hong, S. (2009). Enhancing AUTOSAR methodology to a cotsbased development process via mapping to V-Model," in IEEE international Symposium on industrial embedded SystemsSIES '09., Lausanne, Switzerland, July, 2009. (Lausanne, Switzerland, Ecole Polytechnique Federale de Lausanne), 850-1053.

Kurland, S. D. (2019). Energy use for GWh-scale lithium-ion battery production. Environ. Res. Commun. 2(1), 12001. doi:10.1088/2515-7620/ab5e1e

Levi, M. D., and Aurbach, D. (2005). A comparison between intercalation of Li and $\mathrm{Mg}$ ions into the model Chevrel phase compound (MxMo6S8): impedance spectroscopic studies. J. Power Sources. 146 (1), 349-354. doi:10.1016/j. jpowsour.2005.03.014

Li, L., Bian, Y., Zhang, X., Guan, Y., Fan, E., Wu, F., and Chen, R. (2018). Process for recycling mixed-cathode materials from spent lithium-ion batteries and kinetics of leaching. Waste Manag. 71, 362-371. doi:10.1016/j.wasman.2017.10.028

Li, M., Zhang, X., Li, M., Chen, R., Wu, F., Khalil, A., et al. (2018). The recycling of spent lithium-ion batteries: a review of current processes and technologies. Electrochem. Energ. Rev. 1 (4), 461-482. doi:10.1007/s41918-018-0012-1

Li, M., Lu, J., Ji, X., Li, Y., Saho, Y., Chen, Z., et al. (2020). Design strategies for nonaqueous multivalent-ion and monovalent-ion battery anodes. Nat Rev Mater. 5 (4), 276-294. doi:10.1038/s41578-019-0166-4

Liu, B., Zhang, H., and Zhu, S. (2016). "An incremental V-model process for automotive development," in 23rd asia-pacific software engineering conference: APSEC 2016: proceedings, Hamilton, New Zealand, 6-9 December 2016, 225-232.

Liu, Q., Du, C. Y., Shen, B., and Zuo, P. (2016). Understanding undesirable anode lithium plating issues in lithium-ion batteries. RSC Adv. 6 (91), 88683-88700. doi:10.1039/C6RA19482F

Luntz, A. C., Voss, J., and Reuter, K. (2015). Interfacial challenges in solid-state Li ion batteries. J. Phys. Chem. Lett. 6 (22), 4599-4604. doi:10.1021/acs.jpclett. $5 \mathrm{~b} 02352$

Lv, W., Wang, Z., Cao, H., Sun, Y., Zhang, Y., and Sun, Z. (2018). A critical review and analysis on the recycling of spent lithium-ion batteries. ACS Sustain. Chem. Eng. 6 (2), 1504-1521. doi:10.1021/acssuschemeng.7b03811

Manthiram, A. (2020). A reflection on lithium-ion battery cathode chemistry. Nat. Commun. 11 (1), 1-9. doi:10.1038/s41467-020-15355-0

Mayyas, A., Steward, D., and Mann, M. (2019). The case for recycling: overview and challenges in the material supply chain for automotive li-ion batteries. Sustainable Materials and Technologies. 19, e00087. doi:10.1016/j.susmat.2018. e00087

McKinsey and Company (2018). Metal mining constraints on the electric mobility horizon. Available at: https://www.mckinsey.com/industries/oil-and-gas/ourinsights/metal-mining-constraints-on-the-electric-mobility-horizon.

Melin, H. E. (2019). "State-of-the-art in reuse and recycling of lithium-ion batteries a research review". Available at: http://www.energimyndigheten.se/globalassets/ forskning-innovation/overgripande/state-of-the-art-in-reuse-and-recycling-oflithium-ion-batteries-2019.pdf

Mossali, E., Picone, N., Gentilini, L., Rodrìguez, O., Pérez, J. M., and Colledani, M. (2020). Lithium-ion batteries towards circular economy: a literature review of opportunities and issues of recycling treatments. J. Environ. Manag. 264, 110500. doi:10.1016/j.jenvman.2020.110500
Nassar, N. T., Graedel, T. E., and Harper, E. M. (2015). By-product metals are technologically essential but have problematic supply. Science advances. 1 (3), e1400180. doi:10.1126/sciadv.1400180

Neubauer, J., and Pesaran, A. (2011). The ability of battery second use strategies to impact plug-in electric vehicle prices and serve utility energy storage applications. J. Power Sources. 196 (23), 10351-10358. doi:10.1016/j. jpowsour.2011.06.053

Nishi, Y. (2001). Lithium ion secondary batteries; past 10 years and the future. J. Power Sources. 100 (1), 101-106. doi:10.1016/S0378-7753(01)00887-4

Oeser, D. (2018). Andreas Ziegler, Ansgar Ackva, "Single cell analysis of lithiumion e-bike batteries aged under various conditions. J. Power Sources. 397, 25-31. doi:10.1016/j.jpowsour.2018.06.101

Olivetti, E. A., Ceder, G., Gaustad, G. G., and Fu, X. (2017). Lithium-ion battery supply chain considerations: analysis of potential bottlenecks in critical metals. Joule. 1 (2), 229-243. doi:10.1016/j.joule.2017.08.019

Pistoia, G. Lithium-ion batteries: Advances and applications. Amsterdam: Elsevier, (2014)

Peled, E., and Menkin, S. (2017). "Review-SEI: past, present and future. J. Electrochem. Soc. 164 (7), A1703. doi:10.1149/2.1441707jes

Perkins, G. (2018). Techno-economic comparison of the levelised cost of electricity generation from solar PV and battery storage with solar PV and combustion of bio-crude using fast pyrolysis of biomass. Energy Convers. Manag. 171, 1573-1588. doi:10.1016/j.enconman.2018.06.090

Pillot, C. (2017). The rechargeable battery market and main trends 2011-2020. "Paris: International Battery Seminar and Exhibit.

Quinn, J. B., Waldmann, T., Richter, K., Kasper, M., and Wohlfahrt-Mehrens, M. (2018). Energy density of cylindrical Li-ion cells: a comparison of commercial 18650 to the 21700 cells. J. Electrochem. Soc. 165 (14), A3284. doi:10.1149/2. 0281814jes

Schmuch, R., Wagner, R., Hörpel, G., Placke, T., and Winter, M. (2018). Performance and cost of materials for lithium-based rechargeable automotive batteries. Nat Energy. 3 (4), 267-278. doi:10.1038/s41560-0180107-2

Shi, Y., Chen, G., and Chen, Z. (2018). Effective regeneration of LiCoO 2 from spent lithium-ion batteries: a direct approach towards high-performance active particles. Green Chem. 20 (4), 851-862. doi:10.1039/C7GC02831H

Shin, S. M., Kim, N. H., Sohn, J. S., Yang, D. H., and Kim, Y. H. (2005). Development of a metal recovery process from Li-ion battery wastes. Hydrometallurgy. 79 (3-4), 172-181. doi:10.1016/j.hydromet.2005.06.004

Simon, B., Ziemann, S., and Weil, M. (2015). "Potential metal requirement of active materials in lithium-ion battery cells of electric vehicles and its impact on reserves: focus on Europe," Resources. Conserv. Recycl. 104, 300-310. doi:10. 1016/j.resconrec.2015.07.011

Skeete, J.-P., Wells, P., Dong, X., Heidrich, O., and Harper, G. (2020). Beyond the EVent horizon: battery waste, recycling, and sustainability in the United Kingdom electric vehicle transition. Energy Res. Soc. Sci. 69, 101581. doi:10. 1016/j.erss.2020.101581

Sonoc, A., Jeswiet, J., and Soo, V. K. (2015). Opportunities to improve recycling of automotive lithium ion batteries. Procedia CIRP. 29, 752-757. doi:10.1016/j. procir.2015.02.039

Study on the review of the list of critical raw materials: final report. Luxembourg: Publications Office of the European Union, (2017).

Thielmann, A., Sauer, A., and Wietschel, M. (2015). Gesamt-roadmap lithiumionen-batterien 2030. Karlsruhe: Fraunhofer-Institut für System- und Innovationsforschung ISI.

United Nations Development Programme Available at: http://hdr.undp.org/en/ content/human-development-index-hdi

Vaalma, C., Buchholz, D., Weil, M., and Passerini, S. (2018). A cost and resource analysis of sodium-ion batteries. Nat Rev Mater. 3(4), 1-11. doi:10.1038/ natrevmats.2018.13

Velázquez-Martínez, V., Santasalo-Aarnio, R., and Serna-Guerrero, R. (2019). A critical review of lithium-ion battery recycling processes from a circular economy perspective. Batteries. 5 (4), 68. doi:10.3390/batteries5040068

Vezzini, A. (2014). "Manufacturers, materials and recycling technologies," inLithium-ion batteries: Advances and applications. Editor G. Pistoia (Amsterdam, Netherlands: Elsevier), 529-551. 
Wang, M.-M., Zhang, C.-C., and Zhang, F.-S. (2017). Recycling of spent lithiumion battery with polyvinyl chloride by mechanochemical process. Waste Manag. 67, 232-239. doi:10.1016/j.wasman.2017.05.013

Xiang, H., Zhang, K., Ji, G., Lee, J.B., Changiiand, Z., Chen, X., et al. (2011). Graphene/ nanosized silicon composites for lithium battery anodes with improved cycling stability. Carbon. 49(5), 1787-1796. doi:10.1016/j.carbon.2011.01.002

Xu, G., Han, P., Dong, S., Liu, H., Cui, G., Zou, C., et al. (2017). Li4Ti5O12-based energy conversion and storage systems: status and prospects. Coord. Chem. Rev. 343, 139-184. doi:10.1016/j.ccr.2017.05.006

Yao, Y., Zhu, M., Zhao, Z., Tong, B., Fan, Y., and Hua, Z. (2018). Hydrometallurgical processes for recycling spent lithium-ion batteries: a critical review. ACS Sustain. Chem. Eng. 6(11), 13611-13627. doi:10.1021/acssuschemeng.8b03545

Zaghib, K., Simoneau, M., Armand, M., and Gauthier, M. (1999). Electrochemical study of Li4Ti5O12 as negative electrode for Li-ion polymer rechargeable batteries. J. Power Sources. 81-82, 300-305. doi:10.1016/S0378-7753(99)00209-8

Zheng, F., Kotobuki, M., Song, S., Lai, M. O., and Lu, L. (2018). Review on solid electrolytes for all-solid-state lithium-ion batteries. J. Power Sources. 389, 198-213. doi:10.1016/j.jpowsour.2018.04.022
Zheng, X., Zhu, Z., Lin, X., Zhang, Y., He, Y., Cao, H., and Sun, Z. (2018). A minireview on metal recycling from spent lithium ion batteries. Engineering. 4(3), 361-370. doi:10.1016/j.eng.2018.05.018

Zubi, G., Dufo-López, R., Carvalho, M., and Pasaoglu, G. (2018). The lithium-ion battery: state of the art and future perspectives. Renew. Sustain. Energy Rev. 89, 292-308. doi:10.1016/j.rser.2018.03.002

Conflict of Interest: The authors declare that the research was conducted in the absence of any commercial or financial relationships that could be construed as a potential conflict of interest.

Copyright (C) 2020 Karabelli, Kiemel, Singh, Koller, Ehrenberger, Miehe, Weeber and Birke. This is an open-access article distributed under the terms of the Creative Commons Attribution License (CC BY). The use, distribution or reproduction in other forums is permitted, provided the original author(s) and the copyright owner(s) are credited and that the original publication in this journal is cited, in accordance with accepted academic practice. No use, distribution or reproduction is permitted which does not comply with these terms. 